به كارگيرى الكوريتم فراكاوشى جرخه آب بهمنظور تعيين الكوى بهينه كشت زراعى در مقايسه با الكوريتم زنتيك و مدل برنامهريزى خطى (مطالعه موردى: شبكه آبيارى ورامين)

ناصر كنجى خرمدل '، معصومه عبدوس 'و سيد محمد حسينى موغارى'

(تاريخ دريافت: 0/1//

جكيده

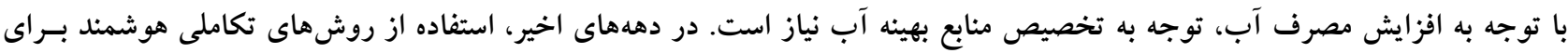

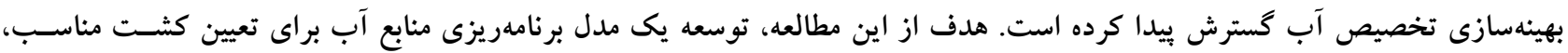

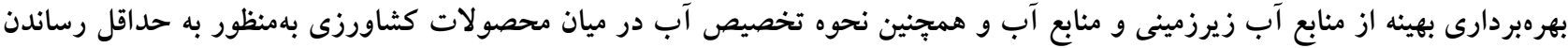

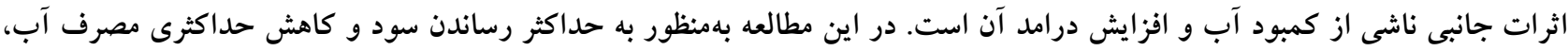

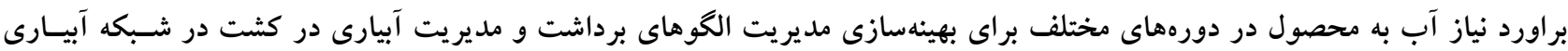

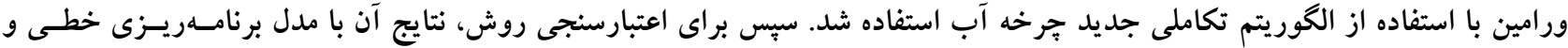

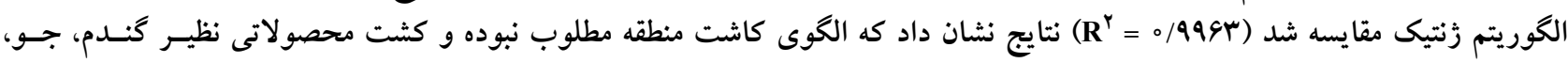

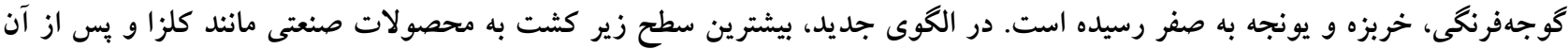

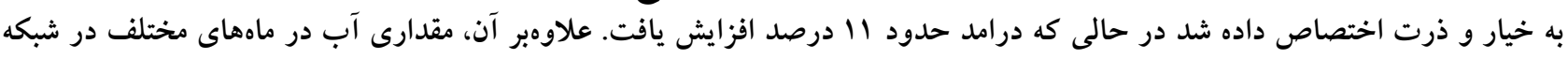

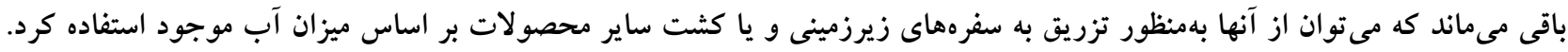

وازههاى كليدى: بهينهسازى فراكاوشى، الكوى كثت، عملكرد محصول، الكوريتم جرخه آب، الكوريتم رُنتيك

1 ا. كروه مهندسى آب، دانشكده كشاورزى، دانشخاه اراى

r. كروه مهندسى منابع آب، دانشكاه تهران

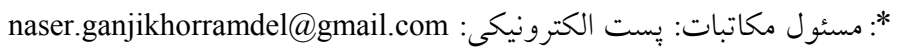




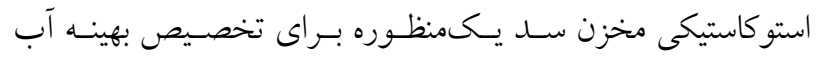

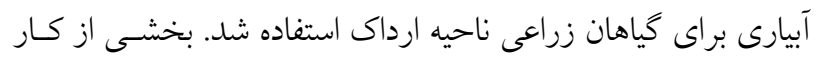

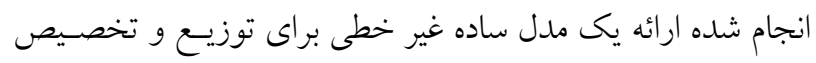

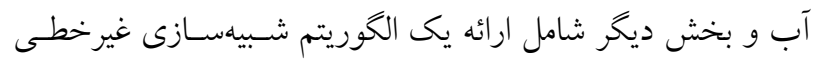

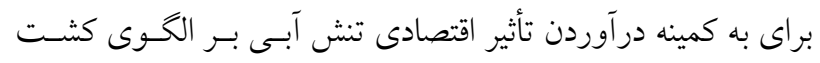

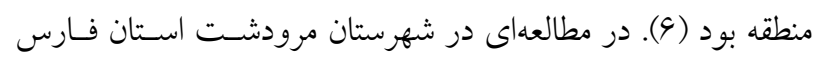

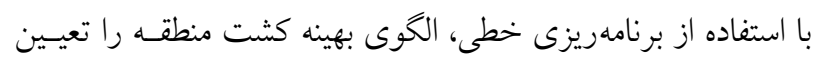

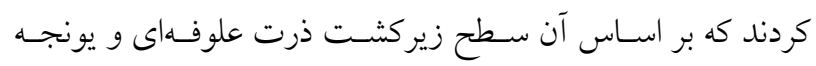

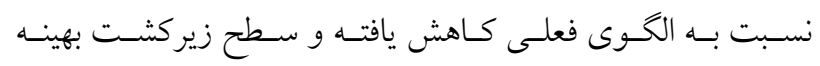

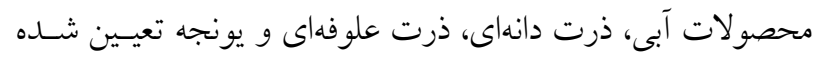

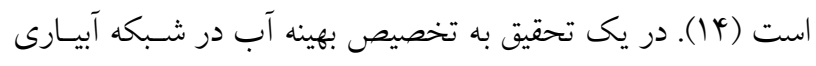

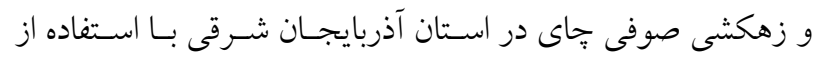

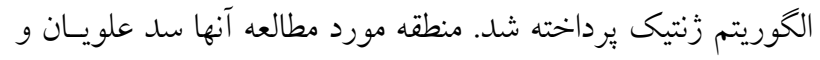

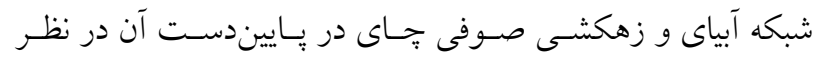

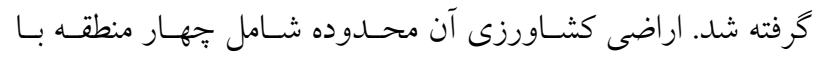

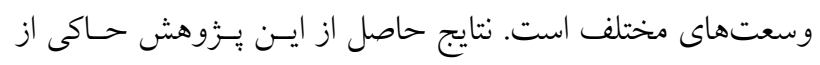

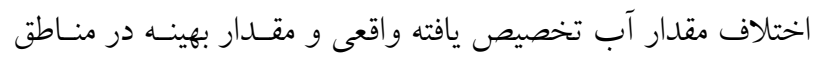

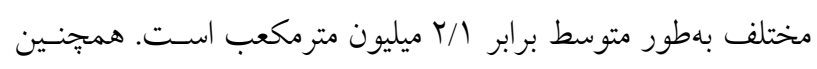



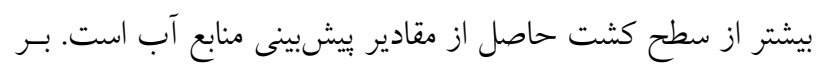



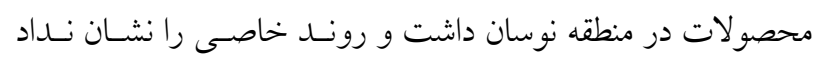

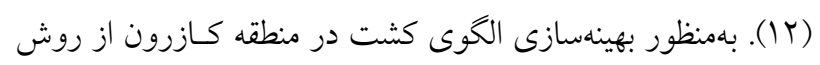

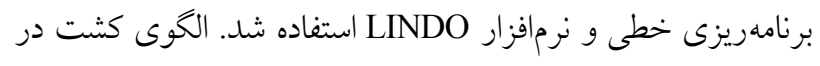

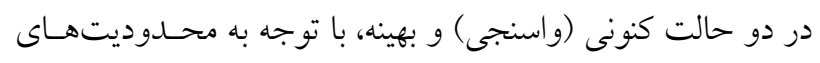

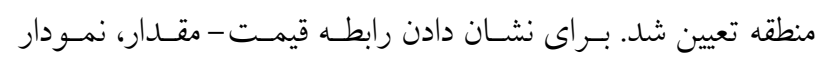



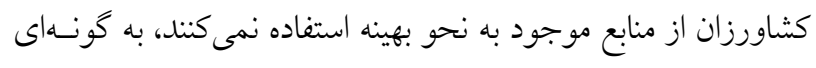

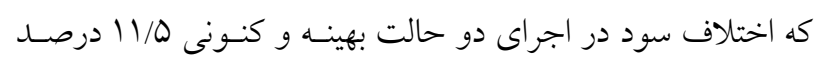

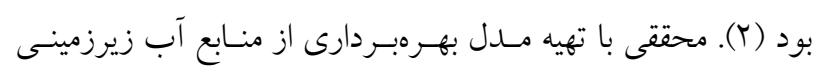

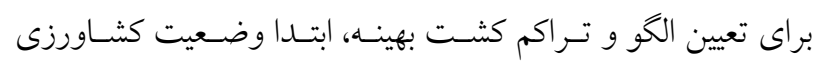

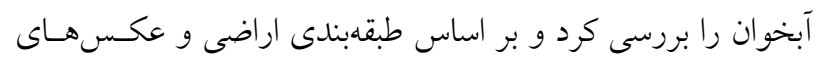

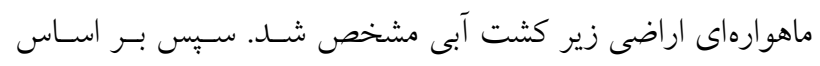

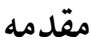

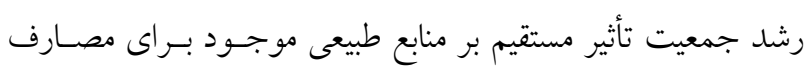

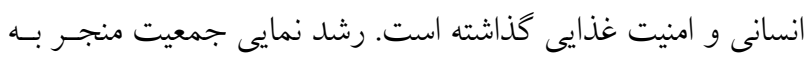
كاهش مساحت كشاورزى خالص در دسترس براى توليد گياه شده

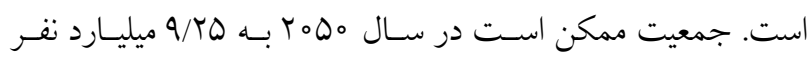

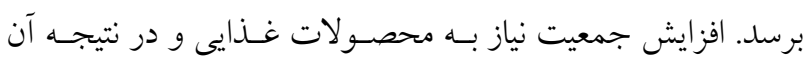

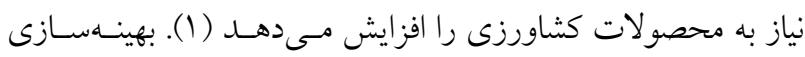
روشى است كه بهوسيله آن بهترين جواب ممكن براى يـك مسئله رئه

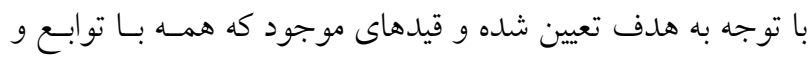

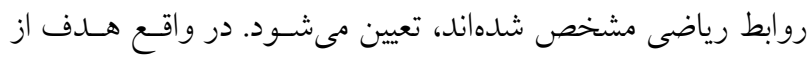

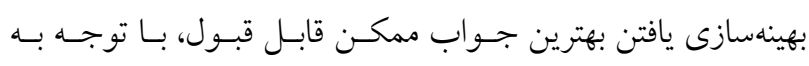

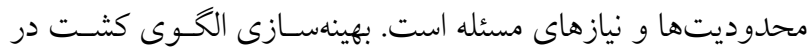

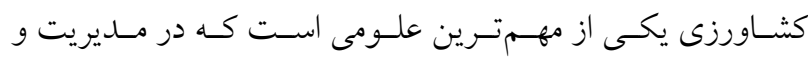

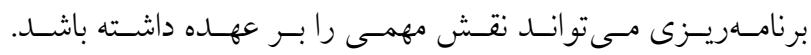
درخصوص بهكاركيرى روش هاى برنامهريزى رياضى در رابطـهـ بـاــا

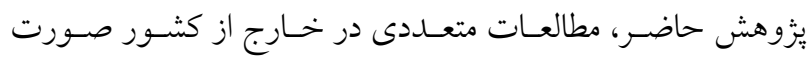

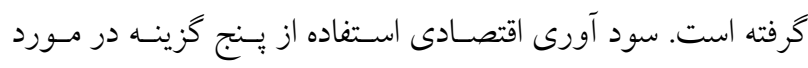

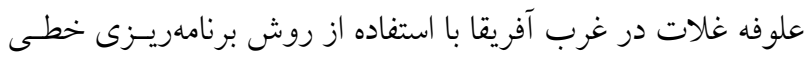

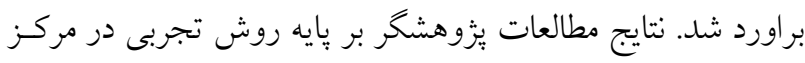



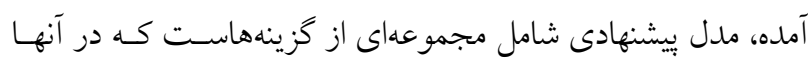

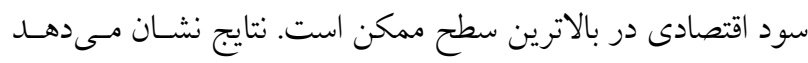

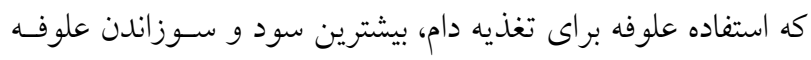



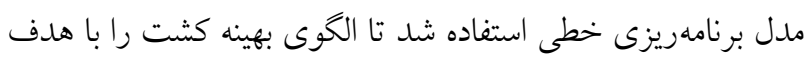

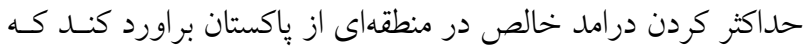

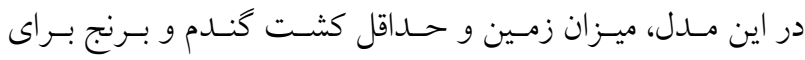

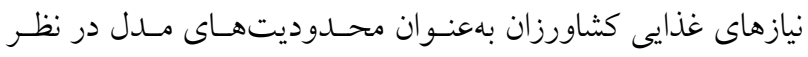

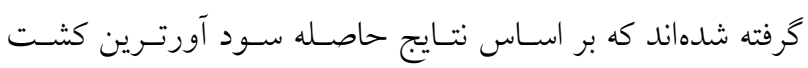

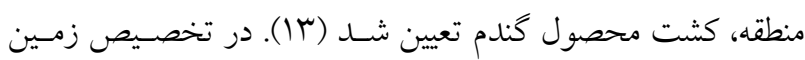

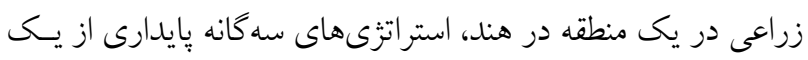

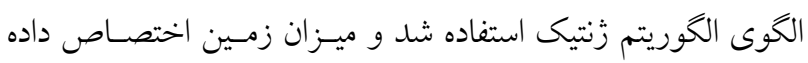

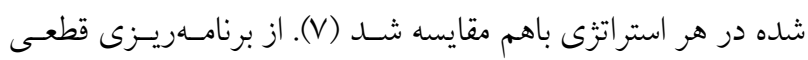


روش بيشنهادى است از طبيعت و بر اسـاس مشـاهدات از فراينـد

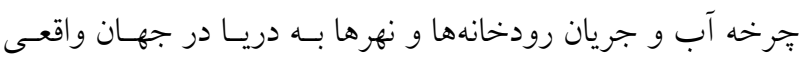
الهام كرفته شده اسـت. كاربردهـاى بسـيار كمسى از ايسن الحـوريتم

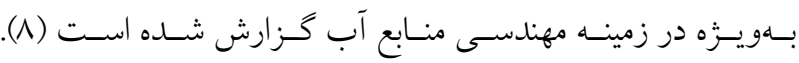

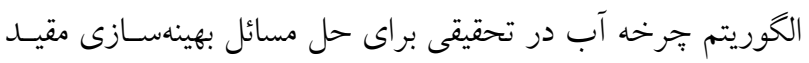

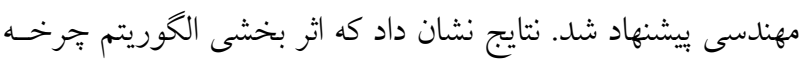

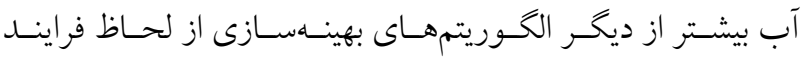

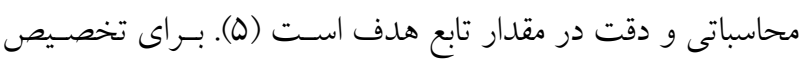

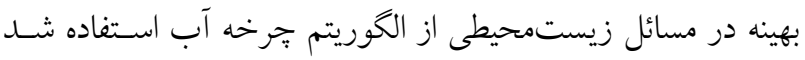



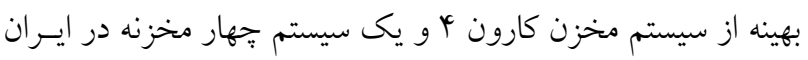

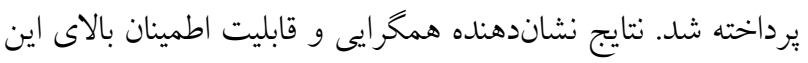





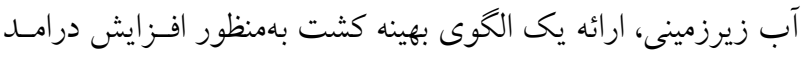

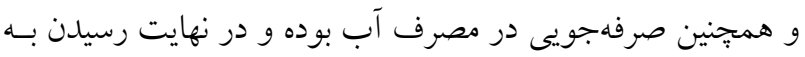

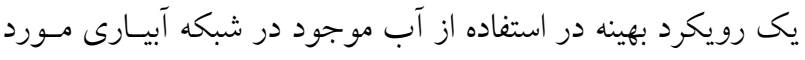

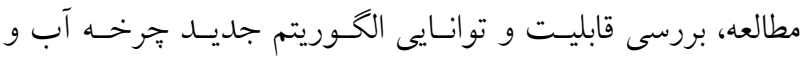

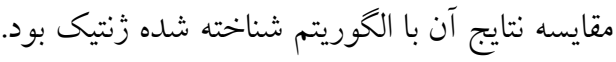

\section{مواد و روشها

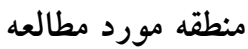

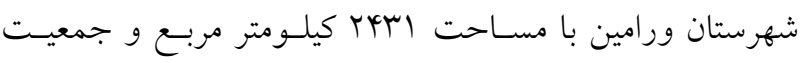

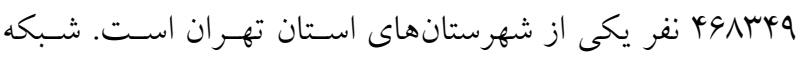

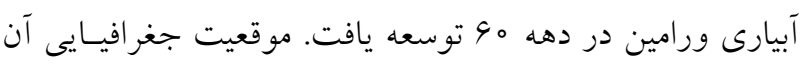

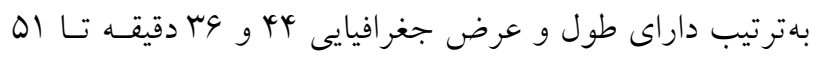

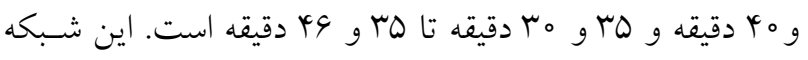

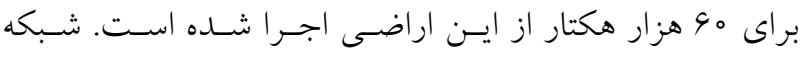

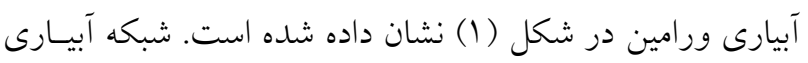
ورامين با هدف تامين آب براى ه 9000 هكتار اراضى شهرستان

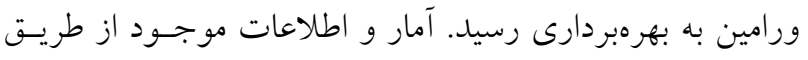
سـازمان جهاد كشـاورزى، سـازمان آب و سـازمان هواشناسى
اطلاعــات موجــود بـــا روش تحليـلـل سلســله مراتــب فــازى Fuzzy Analytical Hierarchy Process)

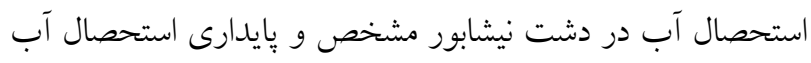

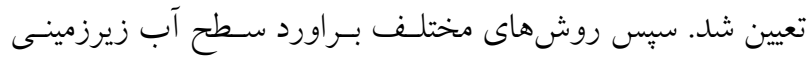

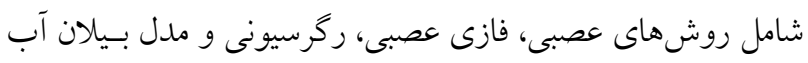

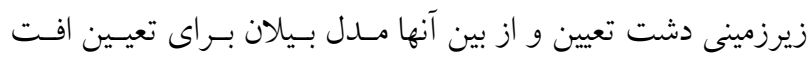

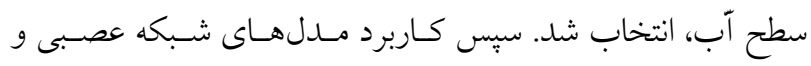

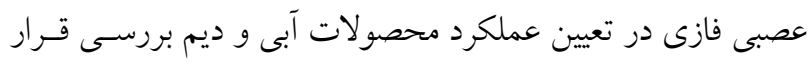

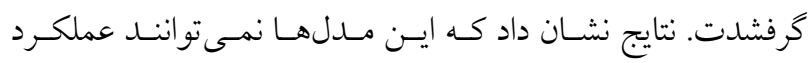

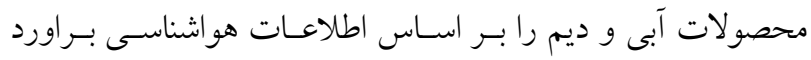



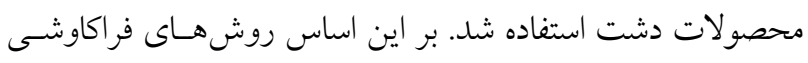
الخــوريتم اجـــاى جمعـى (Particle Swarm Optimization)

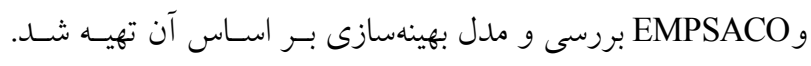

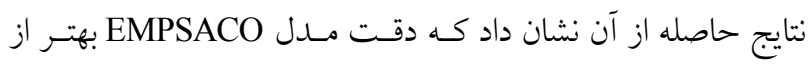

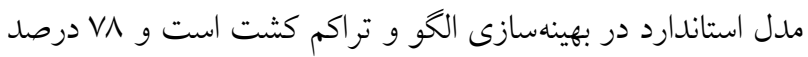

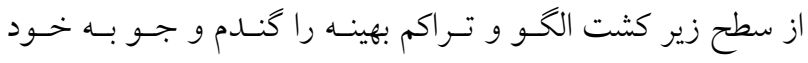

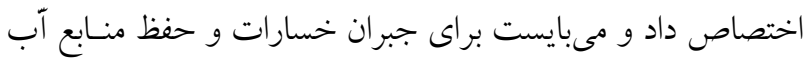

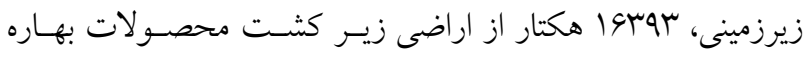

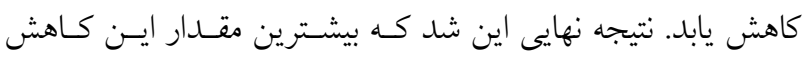

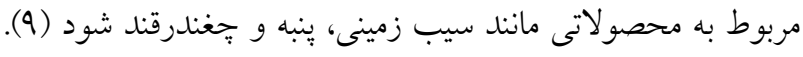

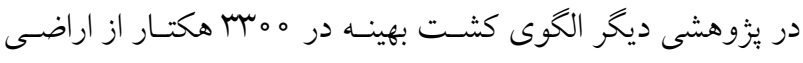

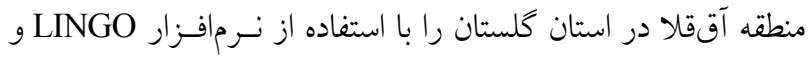



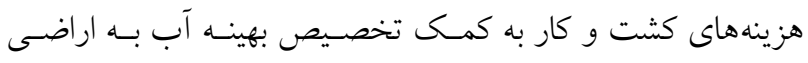

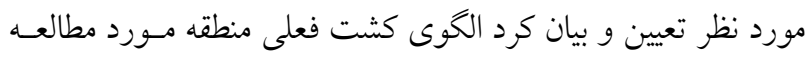

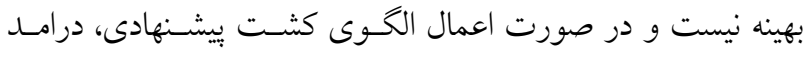

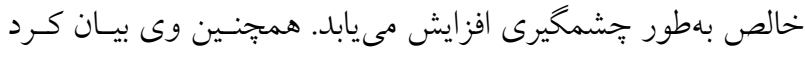

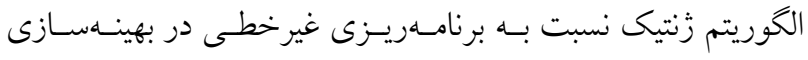

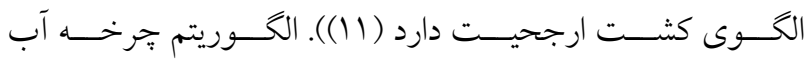
(Water Cycle Algorithm)

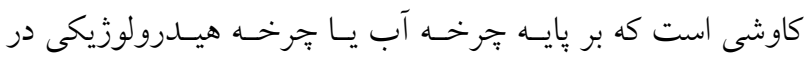






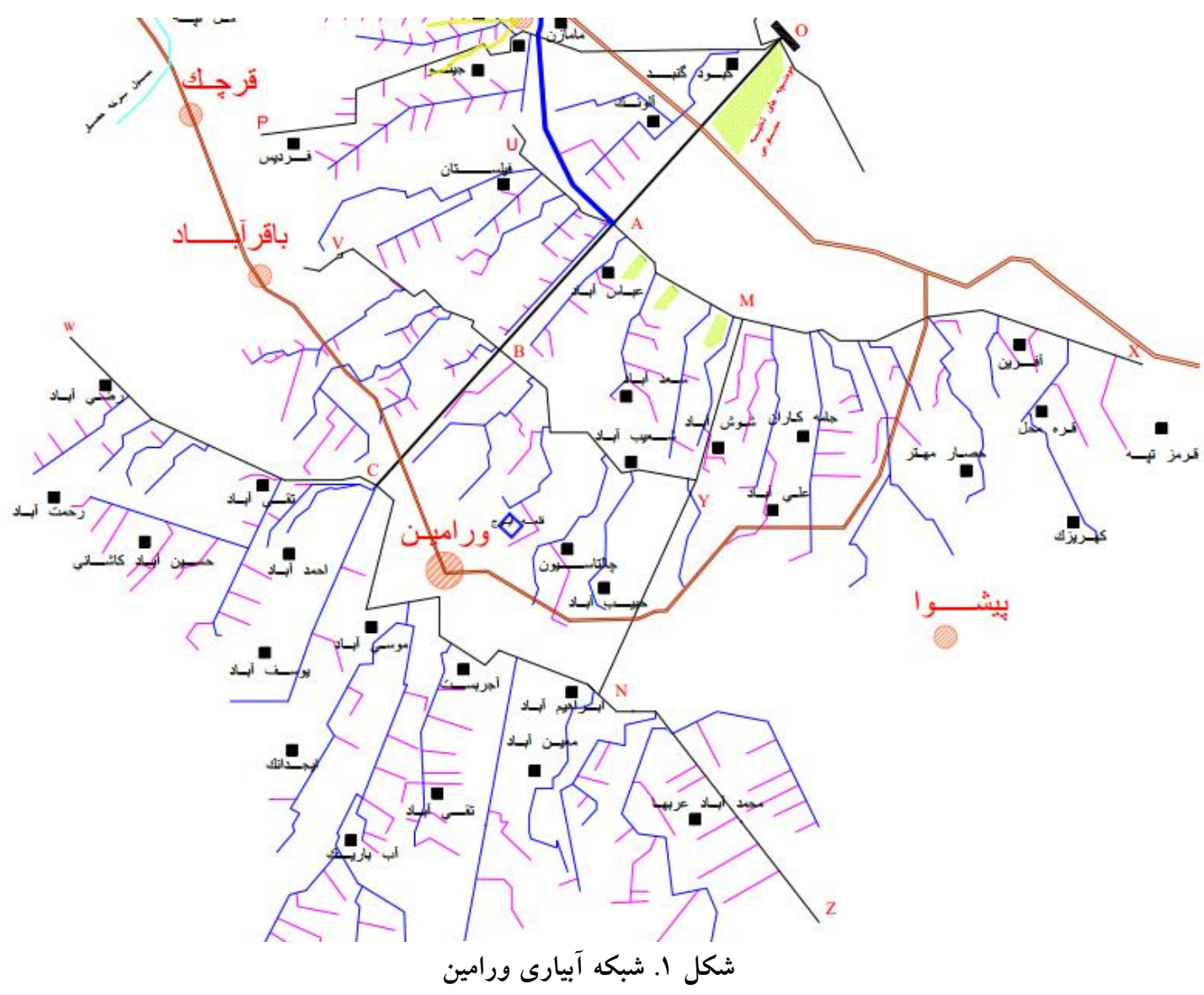

استان تهران (از قبيل سطح زير كشـت، الخـوى كشـت فعلى و ايجاد جمعيت اوليه

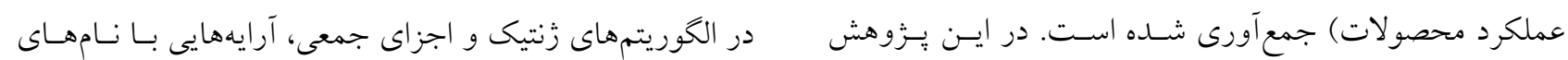

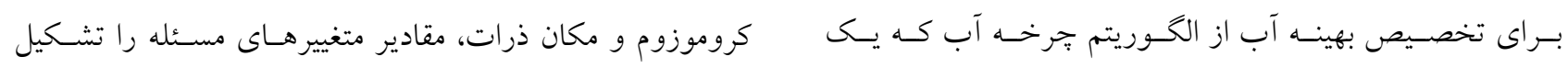

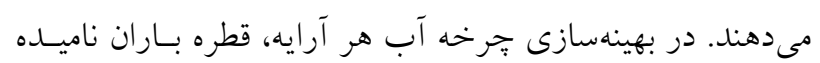
الكوريتم فراكاوشى جديد است، استفاده شده است.

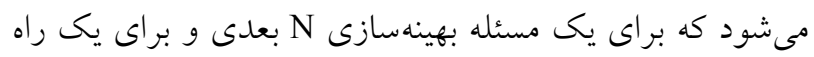
حل بهصورت زير تعريف مىشود.

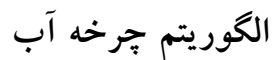
Raindrop $=\left[X_{1} \cdot X_{r} \cdot X_{r} \ldots \ldots . X_{N v a r}\right]$ با در نظر گرفتن NPOP قطره، ماتريس قطرات باران بـه صسورت $\left[\begin{array}{c}\text { Raindrops }_{1} \\ \text { Raindrops }_{2} \\ \text { Raindrops }_{3} \\ \cdot \\ \cdot \\ \cdot \\ \text { Raindrops }_{\mathrm{Npop}}\end{array}\right]$ زير بسط داده مىشود. اين الكوريتم ابتكارى جديد، از رفتار جرخهـهـ آب در طبيعـت الهـام

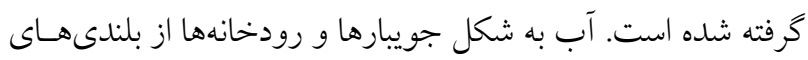

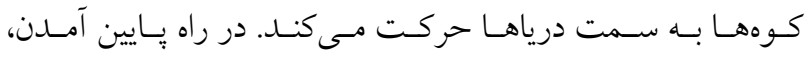

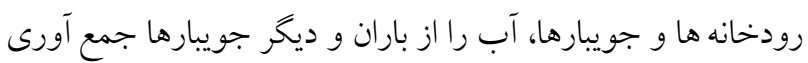

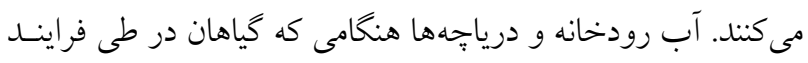

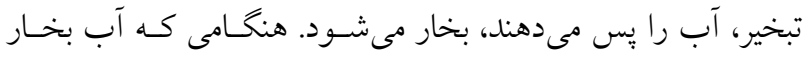



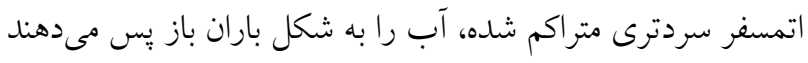
و جويبارها و رودخانههاى جديد توليد مى كنند (9). 
يكى باشد، جويبارها اين توانايى را بيدا مى كنــد كـه در جهات

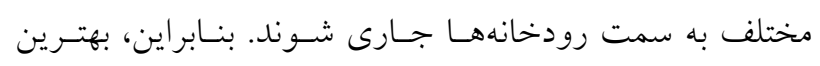
مقدار براى C مقدار دو است. اين مفهوم همجنين مى تواند براى

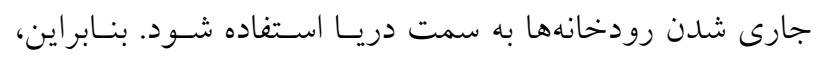

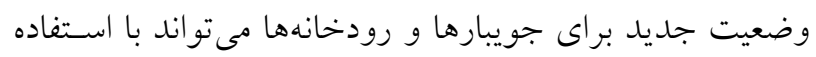
از معادله زير محاسبه شود. $\mathrm{X}_{\text {Stream }}^{\mathrm{i}+1}=\mathrm{X}_{\text {Stream }}^{\mathrm{i}}+\operatorname{rand} \times \mathrm{C} \times\left(\mathrm{X}_{\text {River }}^{\mathrm{i}}-\mathrm{X}_{\text {Stream }}^{\mathrm{i}}\right)$

$\mathrm{X}_{\text {River }}^{\mathrm{i}+1}=\mathrm{X}_{\text {River }}^{\mathrm{i}}+\operatorname{rand} \times \mathrm{C} \times\left(\mathrm{X}_{\text {Sea }}^{\mathrm{i}}-\mathrm{X}_{\text {River }}^{\mathrm{i}}\right)$

كه درآن، rand يك عدد تصادفى يكنواخت توزيع شده بـين

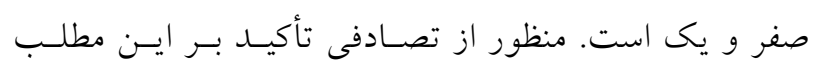

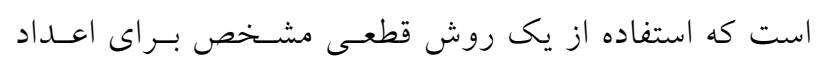
تصادفى، امكان بالقوه تصادفى بودن واقعى را از بين مىبـرد.

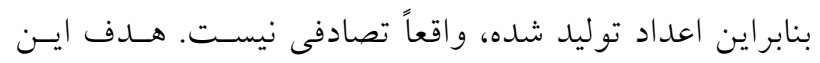



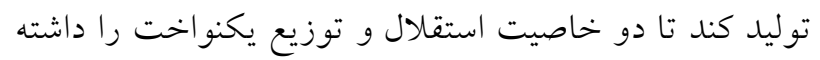
باشند. اخر راه حل ارائه شده توسط يكى نهر، بهتر از رودخانه

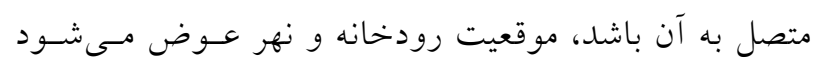

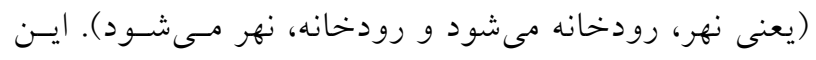

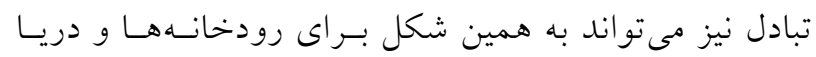

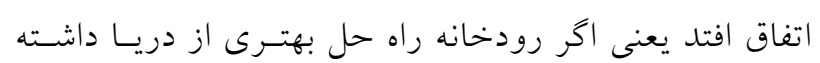
باشد، جابه جا خواهد شد (9).

شرايط تبخير

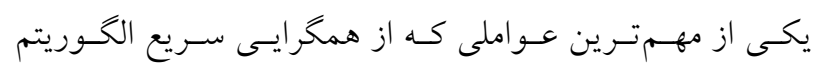

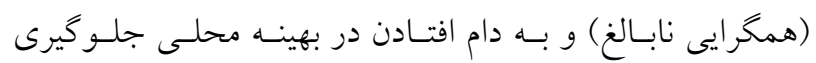

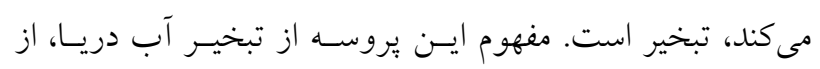

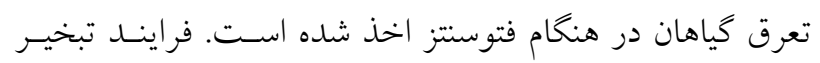

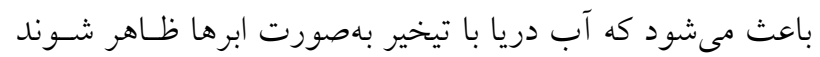

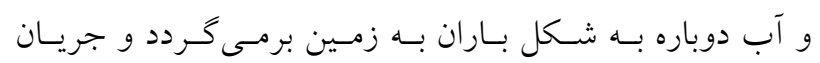

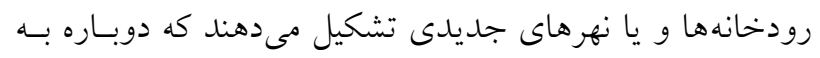

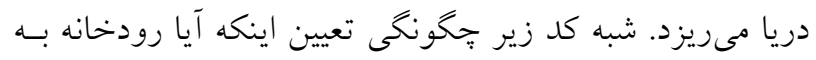

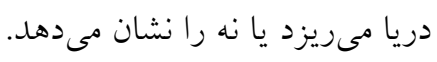

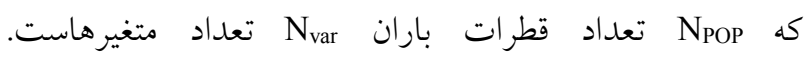
در يكى ماتريس بهصورت تصادفى تشكيلشده از قطرات

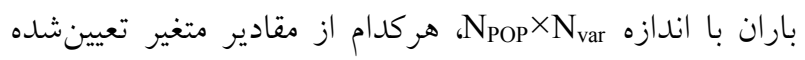

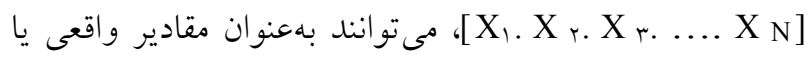

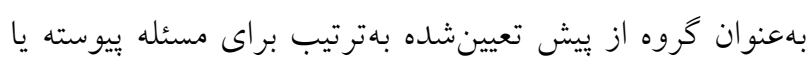

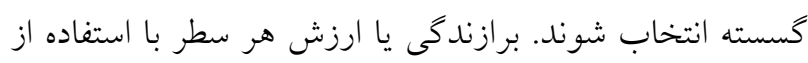
تابع هزينه (C) بهصورت زير بدست مى آيد. $\mathrm{C}_{\mathrm{i}}=\operatorname{Cost}_{\mathrm{i}}=\mathrm{f}\left(\mathrm{x}_{1}^{\mathrm{i}} \cdot \mathrm{x}_{2}^{\mathrm{i}} \cdot \mathrm{x}_{3}^{\mathrm{i}} \ldots . . \mathrm{x}_{\text {Nvar }}^{\mathrm{i}}\right) \mathrm{i}=1,2,3, \ldots, \mathrm{N}_{\text {pop }}(\widetilde{\mu})$

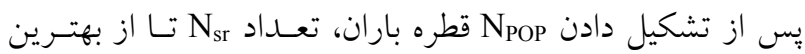



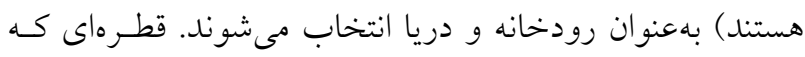

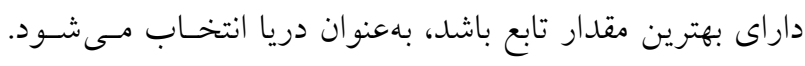

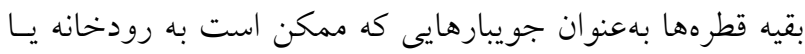

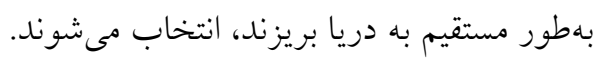

$\mathrm{N}_{\mathrm{sr}}=$ Number of Rivers +1 (sea)

$\mathrm{N}_{\text {stream }}=\mathrm{N}_{\text {POP }}-\mathrm{N}_{\text {sr }}$

بسته به شدت جريان آب، كه از معادله زير محاسبه مسىشود،

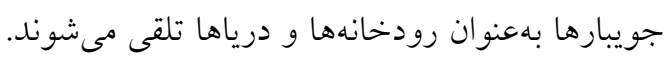

$\mathrm{NS}_{\mathrm{n}}=\operatorname{round}\left\{\left|\frac{\operatorname{cost}_{\mathrm{n}}}{\sum_{\mathrm{i}=1}^{\mathrm{N}_{\mathrm{sr}}} \operatorname{cost}_{\mathrm{i}}}\right|\right\}$

تعـداد جويبارهاسـت كـه بــه رودخخانـه يـا دريـاى معينسى NS

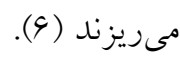

جگگ جنى جارى شدن جويبارها به دريا يا رودخانه حركت يك جويبار بـه سـمت يـك رودخحانـه معسين در امتـداد

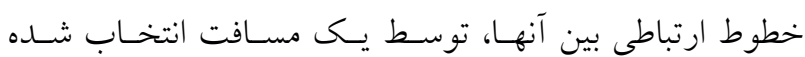
تصادفى و بهصورت زير اعمال مىشود:

$\mathrm{X} \in(0, \mathrm{C} \times \mathrm{d})$

كه C يك مقدار تعريف شـده توسط كساربر و بسين او Y و و

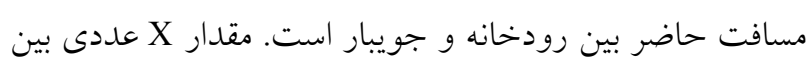

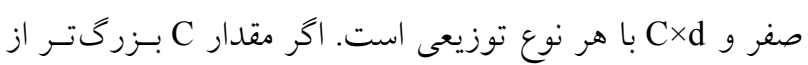


برابر هo ما إنظر كرفته شده است (9).

مدلسازى

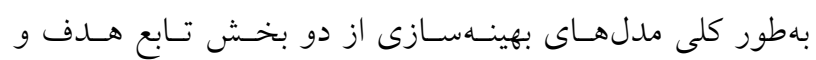

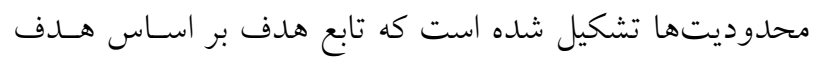

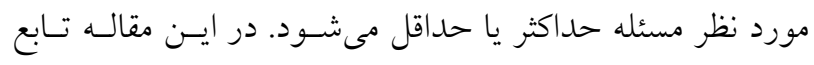
هدف بلصورت زير ارائه شده است. $\max \left(x_{1}, x_{2}, \ldots, x_{n}\right)=\sum_{k=1}^{n} A_{i} P_{i} Y_{i}-\sum_{k=1}^{n} A_{i} C P_{i}-\sum_{k=1}^{n} A_{i} C W W R_{i} \quad(\mid \psi)$ كـه در آن n تعـداد محصـولات، A A

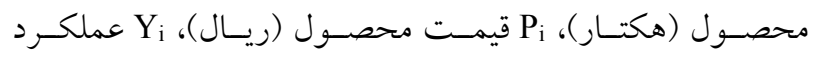



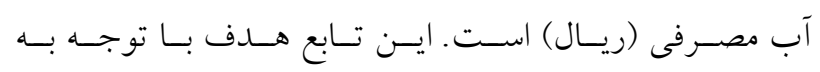

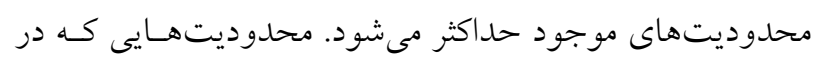



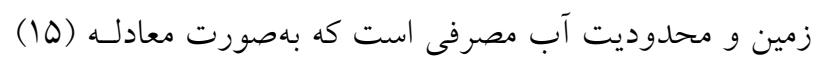

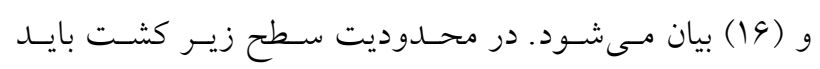

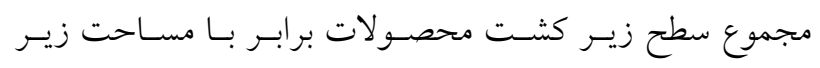



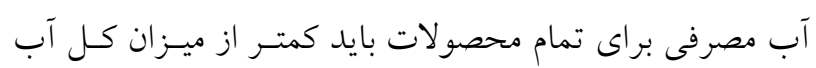
در دسترس باشد.

$\sum_{1}^{\mathrm{n}} \mathrm{A}_{\mathrm{i}} \leq \mathrm{A}$

$\sum_{1}^{\mathrm{n}} \mathrm{A}_{\mathrm{i}} \mathrm{CWR}_{\mathrm{i}} \leq \mathrm{CW}$

در يُزوهش حاضر تبخير و تعرق گياه مرجع از روش فـائو يـنمن

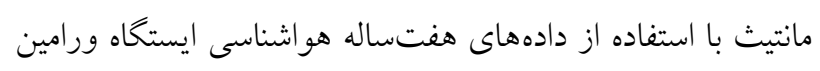

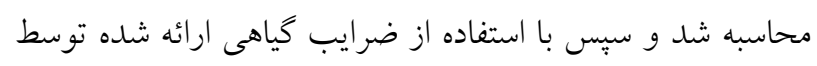
سازمان خواروبار جهانى يا به اختصار فائو در نشـريه وهه، مقـادير

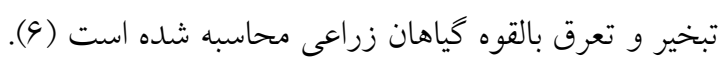

نتايج و بحث روشهاى فراكاوشى بهدليل ماهيت تصادفى آنهـا داراى بارامترهـاى

$$
\text { if }\left|X_{\text {Sea }}^{\mathrm{i}}-X_{\text {River }}^{\mathrm{i}}\right|\left\langle d_{\text {max }} \quad \mathrm{i}=1,2,3, \ldots, \mathrm{n}\right.
$$

كه d d عدد كوجكى (نزديك بـه صـفر ) اسـت. بنـابر اين، اخـر

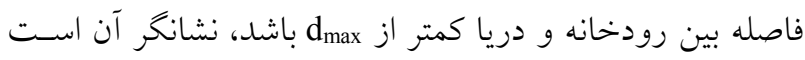

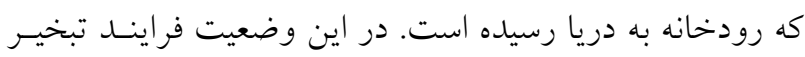
اثر مى كند و همانطور كه در طبيعت ديده مىشوده، بعلد از تبخيـر

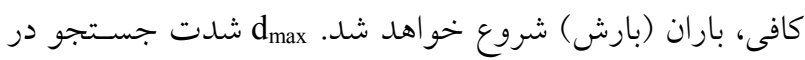

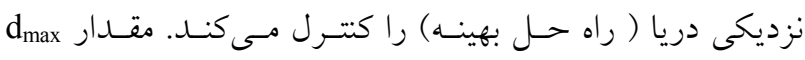
بهصورت زير در هر مرحله كاهش مىيابد (4).

$$
\mathrm{d}_{\max }^{\mathrm{i}+1}=\mathrm{d}_{\text {max }}^{\mathrm{i}}-\frac{\mathrm{d}_{\text {max }}^{\mathrm{i}}}{\text { maxiteration }}
$$

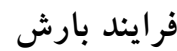

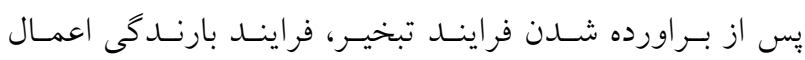

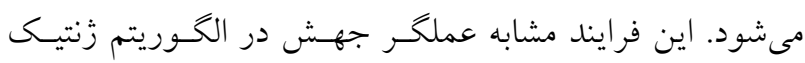

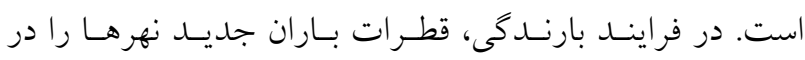

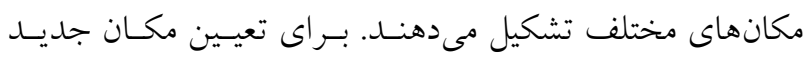

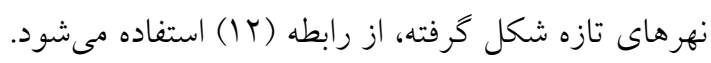
$\mathrm{X}_{\mathrm{Stream}}^{\mathrm{New}}=\mathrm{LB}+\operatorname{randn} \times(\mathrm{UB}-\mathrm{LB})$

كه LB و UB بهترتيب، كران پاييين و بالاى تعريف شده توسط

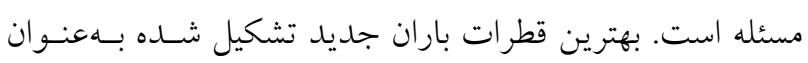

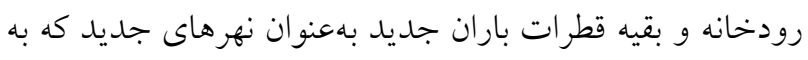

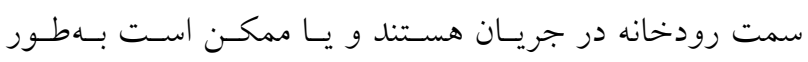

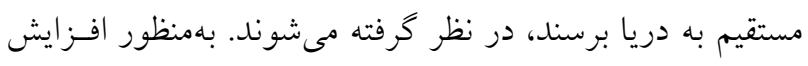


مقيد از رابطه زير استفاده مى شودر.

$\mathrm{X}_{\mathrm{Stream}}^{\mathrm{New}}=\mathrm{X}_{\mathrm{Sea}}+\sqrt{\mu} \times \operatorname{randn}(1, \mathrm{~N})$

ب ضريبى است كه محدودهه جستجوى در نزديكى دريا را نشان

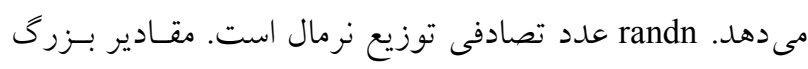

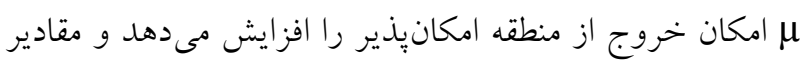

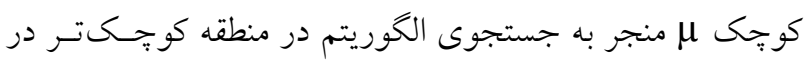

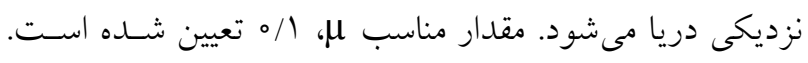

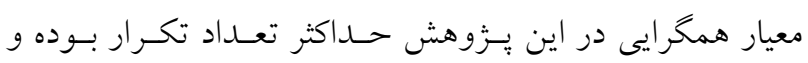


جدول ا. مقادير بارامترهاى مورد استفاده در برنامه الكوريتم جرخه آب

\begin{tabular}{|c|c|c|c|}
\hline تعداد رودخانه & تعداد متغير تصميم & تعداد قطرات & تعداد اجرا \\
\hline ro & 10 & Yoo & 10 \\
\hline
\end{tabular}

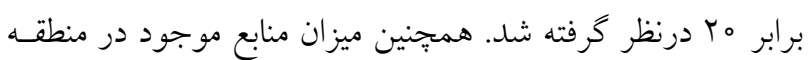

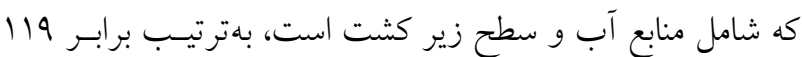

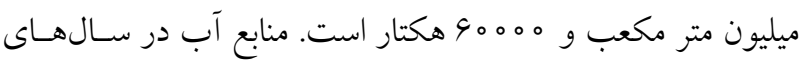
اخير كاهش جشمحيرى داشته است بهطورى كه ميـانخين 9 سـاله

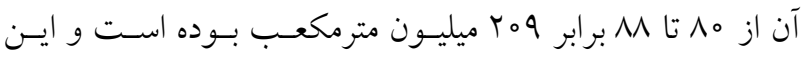

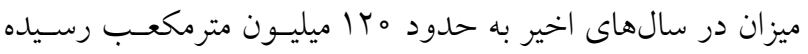

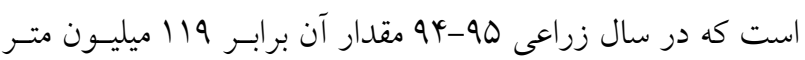

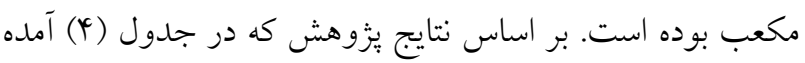

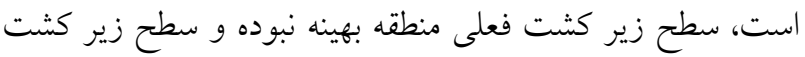

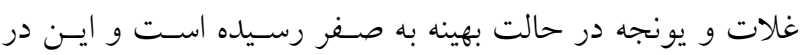

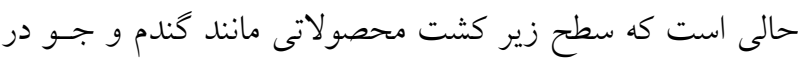

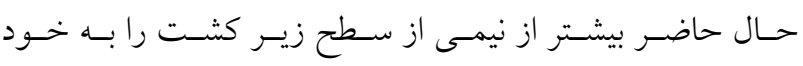

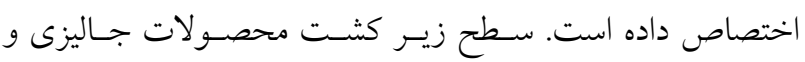

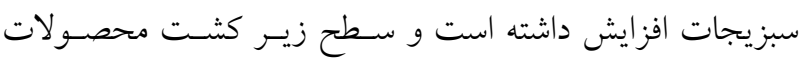

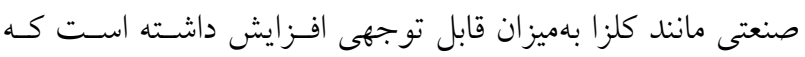

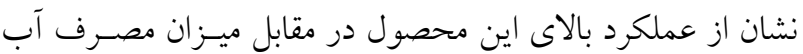
است كه توصيه مىشود براى بهرهورى درسـت از آب و افـزايش سود حاصل از زراعت، به كشـت ايـن محصـول اقــام شـود. در

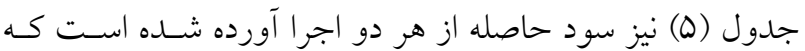

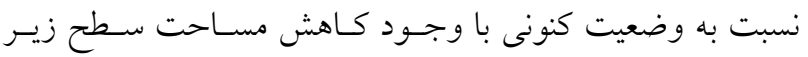
كشت و باقى ماندن مقدارى آب كه بسيار مفيد اسـت، حسـود 11 درصد افز ايش را نشان مىدهد. بر اساس نتايج، در جدول (9) سود حاصله از الكوى كشت

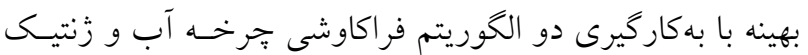
و مدل برنامهريزى خطى نشان داده شــه اسـت. همـانطور كـهـ

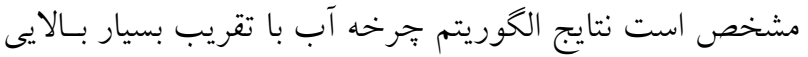

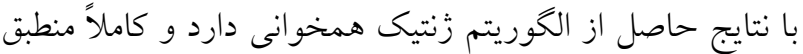

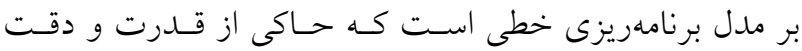

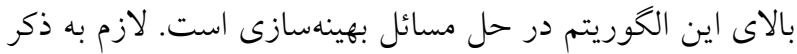

آزادى هستند كه با تغييرات اين بارامترها، عملكرد مــل، همخر ايسى



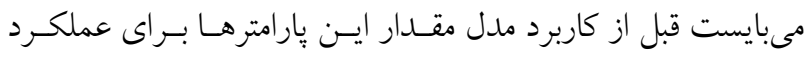

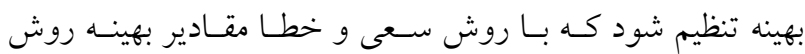

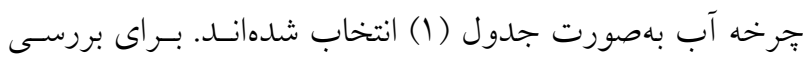

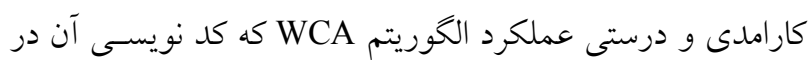

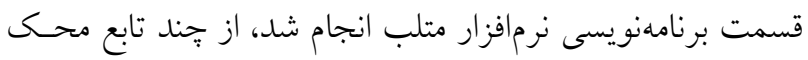

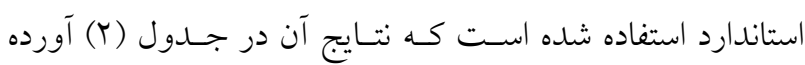



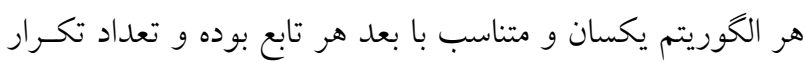

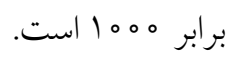
همانطور كه از نتايج جدول (Y) مشاهده مى شود، تأييـد يِيـدا

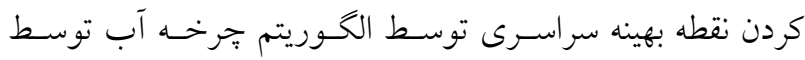

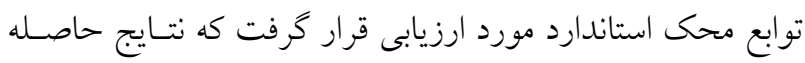

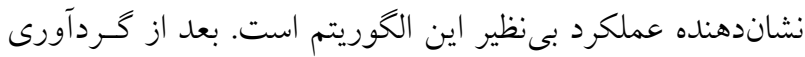



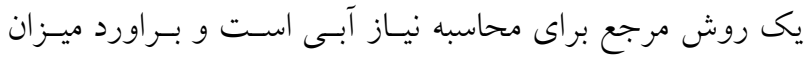

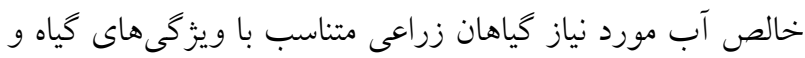

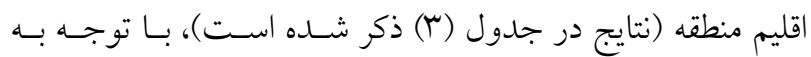
محدوديتها و قيدهاى مسئله، الكوى بهينه اراضى تحت بوشـش إنش

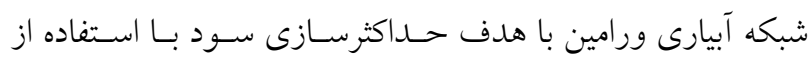

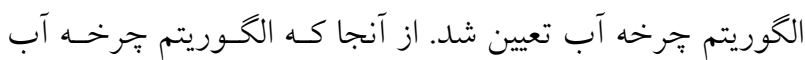



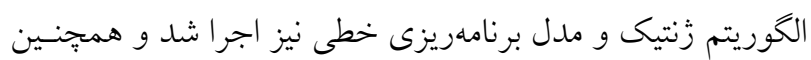

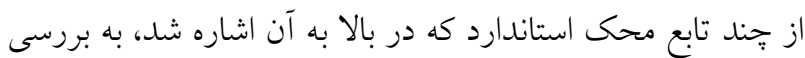



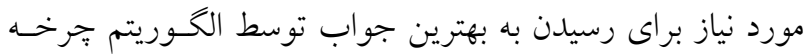



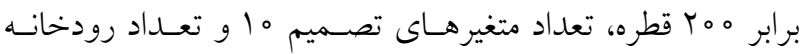


جدول r. - مقايسه عملكرد با استفاده از توابع محك



جدول f. سطح زير كثت به تفكيك محصول

\begin{tabular}{|c|c|c|c|c|c|c|c|}
\hline 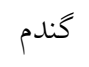 & جو & سبزيجات & محصولات صنعتى & جاليزى & ذرت علوفهاى & يونجه & سطح زير كشت \\
\hline 1100 & 10100 & IKYo & rYo & Yood & $\Delta Q \circ \circ$ & Yooo & هكتار \\
\hline
\end{tabular}


به كارگيرى الكوريتم فراكاوشى جرخه آب بهنظور تعيين الكوى بهينه كشت زراعى...

جدول ه. سطح زير كشت حالت بهينه

\begin{tabular}{|c|c|c|c|c|c|c|c|}
\hline 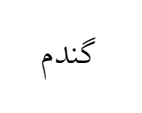 & جو & سبزيجات & محصولات صنعتى & جاليزى & ذرت علوفهاى & يونجه & سطح زير كشت \\
\hline 。 & 。 & lero & IrqY/Ar & $q V \circ D$ & DHFO/A & $\circ$ & جرخه آب \\
\hline DN/GMIGY & VAYMAYVY & $1 / N y$ & $1 Y q 4 \circ / 0$ & $Y V \circ q / D r$ & QTII/KTV & $1 / \mathrm{VV}$ & ز زنتيك \\
\hline 。 & 。 & IKYo & $1 r q Y / A r$ & $q V \circ D$ & $\Delta Y M \circ / \Lambda$ & 。 & زى خطى آب \\
\hline
\end{tabular}

جدول 9. سود حاصل از الكوى كشت بهينه

\begin{tabular}{|c|c|}
\hline سود حاصله ( ريال ) & \\
\hline $0 /$ r Q09TE + Ir & الكوريتم جرخه آب \\
\hline$\Delta / r \circ q r E+I r$ & الكوريتم زنتيك \\
\hline $0 / r 909 T \mathrm{E}+1 T$ & مدل برنامهريزى خطى \\
\hline
\end{tabular}

جدول V. مقدار آب باقيمانده در ماههاى مختلف

\begin{tabular}{|c|c|c|}
\hline آب باقيمانده در شبكه & (آب ورودى به شبكه & ماه \\
\hline 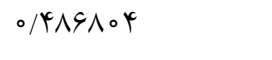 & 9 & فروردين \\
\hline $14 / 101 k r$ & YI & ارديبهشت \\
\hline$\circ$ & 11 & خرداد \\
\hline 。 & 10 & تير \\
\hline G/D৭GMDI & 11 & مرداد \\
\hline G/GYYYQD & 10 & شهريور \\
\hline$\wedge$ & $\wedge$ & مهر \\
\hline V/DITYOY & $\wedge$ & آبان \\
\hline $4 / \wedge \wedge 9099$ & v & آذر \\
\hline Y/OVTQYV & 9 & دى \\
\hline $4 / 094999$ & 9 & بهمن \\
\hline 。 & $\wedge$ & اسفند \\
\hline
\end{tabular}

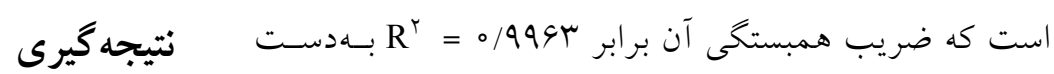

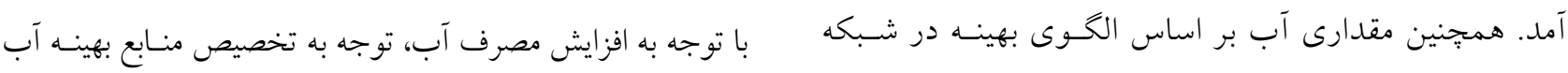
باقى مى ماند كه مقدار آن در جدول (V) آورده شده است. نياز است. در دهلهاى اخير، استفاده از روشهاى تكاملى هوشـمند 


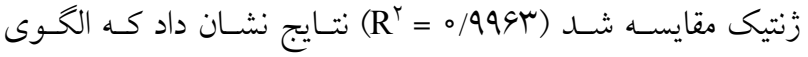

$$
\begin{aligned}
& \text { براى بهينهسازى تخصيص آب كسترش بيدا كرده اسـت. هـدف از } \\
& \text { كاشت منطقه مطلوب نبوده و كشت محصولاتى نظيـر كنــدم، جـو، }
\end{aligned}
$$

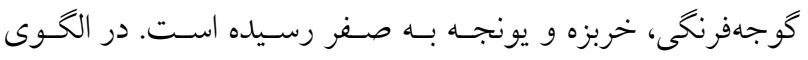

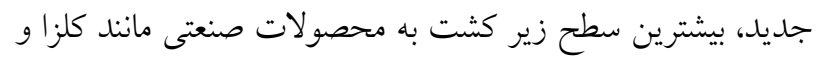

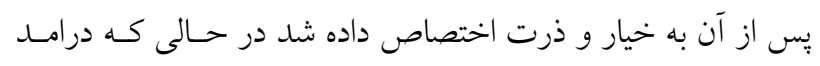

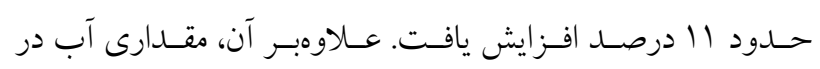

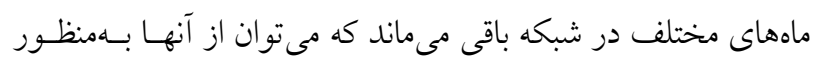

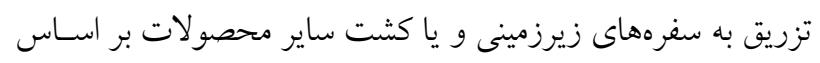

$$
\begin{aligned}
& \text { ميزان آب موجود استفاده كرد. }
\end{aligned}
$$

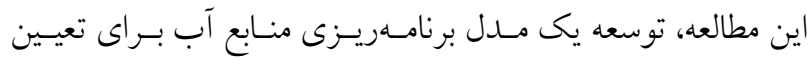

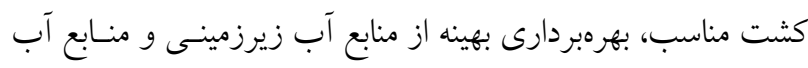

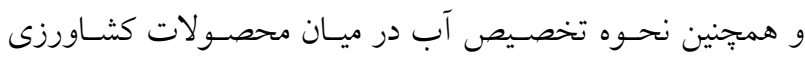

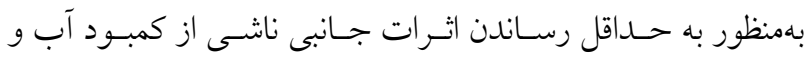

$$
\begin{aligned}
& \text { افزايش درامد آن است. در اين مطالعه بهمنظور به حســاكثر رسـاندان }
\end{aligned}
$$

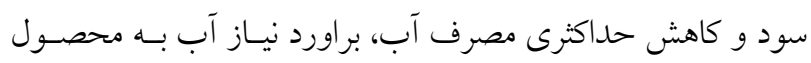



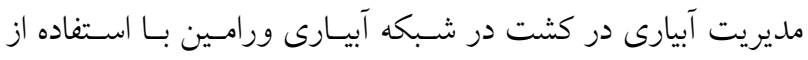

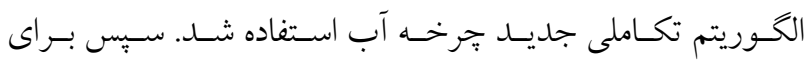

$$
\begin{aligned}
& \text { اعتبارسنجى روش، نتايج آن با مدل برنامهريزى خطى و و الخــوريتم }
\end{aligned}
$$

\section{منابع مورد استفاده}

1. Asadzadeh, A., S. Khodaverdizadeh, K. Beheshti and A. Shomali. 2015. A study of the effect of population growth on per capita GDP in Iran using an ARDL appraoch. Journal of Applied Economics Studies in Iran 4(14): 69-87. (In Farsi).

2. Bagherian, A. and A. Salehi. 2007. Optimization of cropping Pattern in Kazeroon Region using linear programming Method. In: Proceeding of the $6^{\text {th }}$ National Conference of Agricultural Economics. Iranian Agricultural Economics Society. Mashhad. Iran. (In Farsi).

3. Baghipour, R., S. M. Hosseini and Z. Boor. 2014. A water cycle algorithm for optimal allocation of DGs in distribution system considering environmental profit. International. Journal of Mechatronics Electrical and Computer Technology 4(11): 430-454.

4. Bozorg Haddad., O., M. Moravej and H. A. Loaiciga. 2014. Application of the water cycle algorithm to the optimal operation of reservoir systems. Journal of Irrigation and Drainage Engineering 141(5): 1943-4774.

5. Eskandar., H., A. Sadollah, A. Bahreininejad and M. Hamdi. 2012. Water cycle algorithm -a novel metaheuristic optimization method for solving constrained engineering optimization problems. Journal of Computer and Structure 110: $151-166$.

6. Ghahreman, b. 1992. Irrigation water for crops by linear programming optimization expertise stochastic reservoir Single-purpose. Ph.D Thesis, Soil Science, Faculty of Agriculture, Shiraz University.

7. Gopi, A., K. V. Subbaiah and N. R. Kandukuri. 2011. Land allocation strategies through genetic algorithm approach-a case study. Global Journal of Research in Engineering 11(5): 7-14.

8. Hoseini, M and M. Vafaei Jahani. 2012. New evolutionary algorithm based on water cycle in nature. In: Proceeding of the $4^{\text {th }}$ Iranian Conference on Electerical and Electeronics Engineering. Islamic Azad University, Gonabad, Iran. (In Farsi).

9. Khashei Sivki, A. 2011. Developing a pumping model from groundwater resources for optimal cropping pattern and intensification. PhD. Thesis, Irrigation and Drainage, Faculty of Agriculture, Tarbait Modares University. Tehran, Iran. (In Farsi).

10. Lamers, J. 1994. Comparative advantage of single and multi purpose uses of millet in Nigeria. Journal of Agriculture Ecosystem and Environment 7(1): 23-35.

11. Mohsen zade, F. 2012. The effect of cropping patterns to maximize profit and optimize water use efficiency of different methods of planning. MSc. Thesis, Agricultural Sciences and Natural Resources, Gorgan University.

12. Sadradini, A.A. and H. Kiyanfar. 2011. Optimal water allocation for Sufi-chay irrigation and drainage network in East Azerbaijan province of Iran using genetic algorithm. Journal of Irrigation and water Engineering 2(5):52-61. (In Fasi).

13. Singh, D. K., C. S. Jaiswal, K. S. Reddy, R. M. Singh and D. M. Bandarkar. 2001. Optimal cropping pattern in a canal command area. Journal of Agriculture Water Management 50: 1-8.

14. Torkamani, J. and M. HajiRahimi. 1997. Apply of goal programming in detemining the optimal program of agricultural units (Case study:West Azerbaijan Province). Journal of Agricultural Economics and Development 20: 39-51. (In Farsi). 


\title{
Using of Metaheuristic Water Cycle Algorithm in order to Determine Optimal Crop Cultivation across of Genetic Algorithm and linear programming (Case Study: Varamin Irrigation Network)
}

\author{
N. Ganji Khorramdel ${ }^{1 *}$, M. Abdoos ${ }^{1}$ and S. M. Hoseini Mooghaari ${ }^{2}$
}

(Received: January 30-2018; Accepted: August 14-2018)

\begin{abstract}
Due to water use increasing, attention to optimal water resources allocation is needed. In recent decades, the use of intelligent evolutionary methods for optimization of water allocation was focused more by researchers. The aim of this study is to development on water resources planning model that determined the proper cultivation, optimal exploitation of groundwater and surface water resources although water allocation among crops is a way to minimize the adverse effects of dehydration and increase its revenue. In this study, for maximizing profits, estimating crop water requirements at different periods to optimize the management of cropping patterns and irrigation management in cultivation in Varamin irrigation network using a new evolutionary algorithm was called the water cycle. Then for validation of this method is that a new approach and ensure the integrity of its performance Its results are compared with a genetic algorithm model and linear programming as our base $\left(\mathrm{R}^{2}=0.9963\right)$. The results showed that the area cropping pattern was not optimal and the area under cultivation of crops such as wheat, barley, tomatoes, Bamjan, melon, alfalfa reaches zero and the new paradigm of the largest area under cultivation to industrial goods and then was assigned cucumbers. While our revenues have increased about 11 percent. In addition to amount of water in different months remain in the network that can be used for many that such as injection into underground aquifers or other crops based on the amount of water available.
\end{abstract}

Keywords: Metha-heuristic Optimization, Cultivation Pattern, Crop Yield, Water Cycle Algorithm, Genetic Algorithm

1. Department of Water Engineering, Faculty of Agriculture, Arak University, Arak, Iran.

2. Department of Water Resources Engineering, Tehran University, Karaj, Iran.

*: Corresponding Author, Email: naser.ganjikhorramdel@gmail.com 